\section{Report of Spectroscopy Findings Not the First}

Foerster et $\mathrm{al}^{1}$ were right to report their proton MR spectroscopy findings in children with hepatic encephalopathy but were wrong to claim to be the first. I draw your attention to their article, in which the authors make the statement, "Our study is the first...." This kind of statement adds nothing to the scientific or educational value of the report and is especially concerning because it is not true. In 1995, we used proton MR spectroscopy to assess children with hepatic encephalopathy before and after liver transplantation. ${ }^{2}$ Both articles show that brain spectroscopy is helpful in assessing hepatic encephalopathy in children.

\section{References}

1. Foerster BR, Conklin LS, Petrou M, et al. Minimal hepatic encephalopathy in children: evaluation with proton MR spectroscopy. AJNR Am J Neuroradiol 2009;30:1610-23. Epub 2009 Jun 9

2. McConnell JR, Antonson DL, Ong CS, et al. Proton spectroscopy of brain glutamine in acute liver failure. Hepatology 1995;22:69-74

J.R. McConnell Greater Regional Medical Center Creston, Iowa

DOI 10.3174/ajnr.A208 